\title{
Viral metagenomic analysis of bushpigs (Potamochoerus larvatus) in Uganda identifies novel variants of Porcine parvovirus 4 and Torque teno sus virus 1 and 2
}

\author{
Anne-Lie Blomström ${ }^{1 *}$, Karl Ståhl ${ }^{1,2}$, Charles Masembe ${ }^{3}$, Edward Okoth ${ }^{4}$, Ademun Rose Okurut ${ }^{5}$, Patrick Atmnedi ${ }^{6}$, \\ Stephen Kemp ${ }^{4}$, Richard Bishop ${ }^{4}$, Sándor Belák ${ }^{1,2}$ and Mikael Berg ${ }^{1}$
}

\begin{abstract}
Background: As a result of rapidly growing human populations, intensification of livestock production and increasing exploitation of wildlife habitats for animal agriculture, the interface between wildlife, livestock and humans is expanding, with potential impacts on both domestic animal and human health. Wild animals serve as reservoirs for many viruses, which may occasionally result in novel infections of domestic animals and/or the human population. Given this background, we used metagenomics to investigate the presence of viral pathogens in sera collected from bushpigs (Potamochoerus larvatus), a nocturnal species of wild Suid known to move between national parks and farmland, in Uganda.

Results: Application of 454 pyrosequencing demonstrated the presence of Torque teno sus virus (TTSuV), porcine parvovirus 4 (PPV4), porcine endogenous retrovirus (PERV), a GB Hepatitis C-like virus, and a Sclerotinia hypovirulence-associated-like virus in sera from the bushpigs. PCR assays for each specific virus combined with Sanger sequencing revealed two TTSuV-1 variants, one TTSuV-2 variant as well as PPV4 in the serum samples and thereby confirming the findings from the 454 sequencing.

Conclusions: Using a viral metagenomic approach we have made an initial analysis of viruses present in bushpig sera and demonstrated for the first time the presence of PPV4 in a wild African Suid. In addition we identified novel variants of TTSuV-1 and 2 in bushpigs.
\end{abstract}

\section{Background}

Wild animals are carriers of a number of pathogens that have the potential to infect the human population and/ or domestic animals. The intensity of contact between wildlife, livestock and human population is increasing due to a number of factors, primarily human and livestock population growth leading to encroachment onto wildlife habitat $[1,2]$. During recent decades a number of pathogen crossovers from wildlife to humans and livestock have occurred resulting in emerging diseases, such as SARS, Hantavirus Pulmonary syndrome 1, Nipah virus disease 1, and Hendra virus-induced diseases

\footnotetext{
* Correspondence: anne-lie.blomstrom@slu.se

1 Department of Biomedical Sciences and Veterinary Public Health, Section of Virology, Swedish University of Agricultural Sciences, Uppsala, Sweden Full list of author information is available at the end of the article
}

among others. However, it is also evident that transmission can occur both ways i.e. pathogens may spill-over to wildlife from humans and/or from livestock. One example of this is the spill-over of Canine distemper virus from domestic dogs (Canis familiaris) to African wild dogs (Lycaon pictus) in Serengeti in 1991 leading to local extinction of wild dogs in the area [2]. Apart from being carriers of novel viruses with the potential to cause disease in naïve domestic hosts, wildlife may also act as reservoirs for known viral pathogens - for example there are a number of wildlife reservoirs for foot and mouth disease virus such as African buffalo (Syncerus caffer), reindeer (Rangifer tarandus) and wild boar (Sus scrofa) [3]. However, information on the viral flora in wildlife is typically scarce or non-existent.

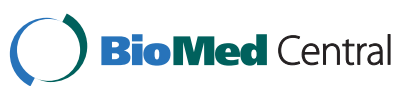


Traditional viral detection methods, such as virus isolation, are often hindered by the inability to grow virus in cell culture. The divergence of many viruses and absence of a common viral marker gene makes detection difficult using standard molecular techniques including PCR and microarray as they are frequently targetspecific through the use of specific primers, probes and/ or antibodies. Viral metagenomics is a sequence, and culture-independent approach that has proven to be a valuable tool for the investigation not only of diseases of unknown etiology but also of the complete viral flora of different reservoirs and vectors. By providing insights into a wide range of unknown potential pathogens and revealing novel aspects of biodiversity, metagenomics is able to detect and characterise novel pathogens [4-6].

In many rural parts of the developing world, domestic livestock are kept in free-range systems, potentially allowing contact with wild animals. In some parts of Uganda, free-range scavenging by pigs is frequent. At the same time wild species of suidae such as bushpigs (Potamochoerus larvatus), with a wide distribution in Eastern and Southern Africa, live and move at the interface between the national parks and the farmland where there is an opportunity for interaction and sharing of pathogens with domestic relatives. Bushpigs are considered to be possible natural reservoirs for African swine fever virus [7], but less is known about what other viruses bushpigs might carry. Therefore, to investigate whether bushpigs are carriers of known and or unknown porcine viruses we have in this study investigated the viral flora of bushpig sera.

\section{Results and discussion}

A total of 171,466 reads were obtained from the 454sequencing run, and after assembly 4,441 contigs were created while 32,863 reads remained unmatched (singletons). Although blastn and blastx analysis showed that a majority of the sequences were non-viral, 35 contigs and singletons sequences were identified as viral sequences (Table 1). The high percentage of host genetic sequences

Table 1 Viral hits of the 454 reads after assembly and blastn/x searches

\begin{tabular}{lll}
\hline Virus hit & Blastn identity & Blastx identity \\
\hline TTSuV-1 & $75-83 \%$ & $48-75 \%$ \\
TTSuV-2 & $68-85 \%$ & $40-86 \%$ \\
PPV4 & No hit - 72\% & $40-76 \%$ \\
GB Hepatitis C virus & No hit & $33 \%$ \\
Sclerotinia hypovirulence & $78 \%$ & $71 \%$ \\
associated virus & & \\
Porcine endogenous retrovirus & $80-95 \%$ & $86-89 \%$ \\
\hline
\end{tabular}

The table shows the sequence similarity that the 454 reads, identified as viral sequences through blastn and blastx searches, had to best available hit in GenBank. found despite of the nuclease treatment prior to sequencing demonstrates the difficulties of completely reducing the background of the host as discussed in the review by Blomström A-L 2011 [4]. Most viral hits showed closest similarity to known pig viruses such as, Torque teno virus (TTSuV) and porcine parvovirus 4 (PPV4). By design of primers based on the sequences obtained from the 454-sequencing run, PCR assays were established to verify the presence of these viruses. These PCR assays confirm the presence of TTSuV1, TTSuV2, PPV4, and the porcine endogenous retrovirus (PERV). The GB Hepatitis C-like, and the Sclerotinia hypovirulence associated like virus, on the other hand, were not detected by the PCR approach, possibly due to the low concentration of these viruses in the samples as only one sequencing read was found for each among the total 171,466 reads obtained from the 454-sequencing run. Also it is possible that in some cases sequencing errors led to primer mismatches.

\section{Parvovirus}

Parvoviruses are small single-stranded linear DNA viruses with a genome of approximately 5000 nucleotides, which have been found in a number of species such as human, swine, cattle and gorilla [8]. In swine, porcine parvovirus (PPV) is a known agent that causes reproductive failure [9]. However, in recent years a number of new parvoviruses - porcine hokovirus ( $\mathrm{PHoV})[10]$, porcine bocavirus (PBoV) [11] and porcine parvovirus 4 (PPV4) [12] - have been discovered in pigs, with their potential involvement in disease currently unknown.

The parvovirus sequences discovered in the investigated bushpigs showed closest similarity to PPV4. Porcine parvovirus 4 was originally discovered in 2010 in samples collected from pigs in North Carolina in 2005 after an outbreak of acute-onset of disease with high mortality [12]. Subsequently, PPV4 was reported in pigs in China where $1.84 \%$ of the investigated pigs were PPV4 positive [13]. The genome of parvoviruses consists of two major open reading frames (ORF) encoding the non-structural and the capsid proteins. However, the genomes of PPV4 as well as of PBoV contain an additional third ORF [12]. The parvovirus sequences obtained from this study could be found in the capsid and in the non-structural ORF. All reads classified as parvovirus gave significant similarity to PPV4 through Blastx searches. A PCR with primers designed to amplify PPV4-like sequences from the original extracted genetic material showed the presence of this virus in one of the three bushpig sera. Sequencing of the PCR product (GenBank accession number: JQ277337) confirmed correct amplification and sequence analysis showed that at protein level (84 amino acids), the product displayed a 75.9-77.1\% sequence similarity to the PPV4 sequences 
available in GenBank. In addition, the phylogenetic tree generated from these data (Figure 1) grouped the sequence with PPV4 when analysed together with sequences from all the different parvovirus genera (Parvovirus, Erythrovirus, Dependovirus, Amdovirus and Bocavirus) and PPV4. However, the tree also confirms the divergence of the bushpig PPV4 from the other PPV4.

PPV4 has previously been reported in domestic pigs only in USA and China $[12,13]$. However with this study we show the presence of a PPV4 variant in a wild suid in Uganda.

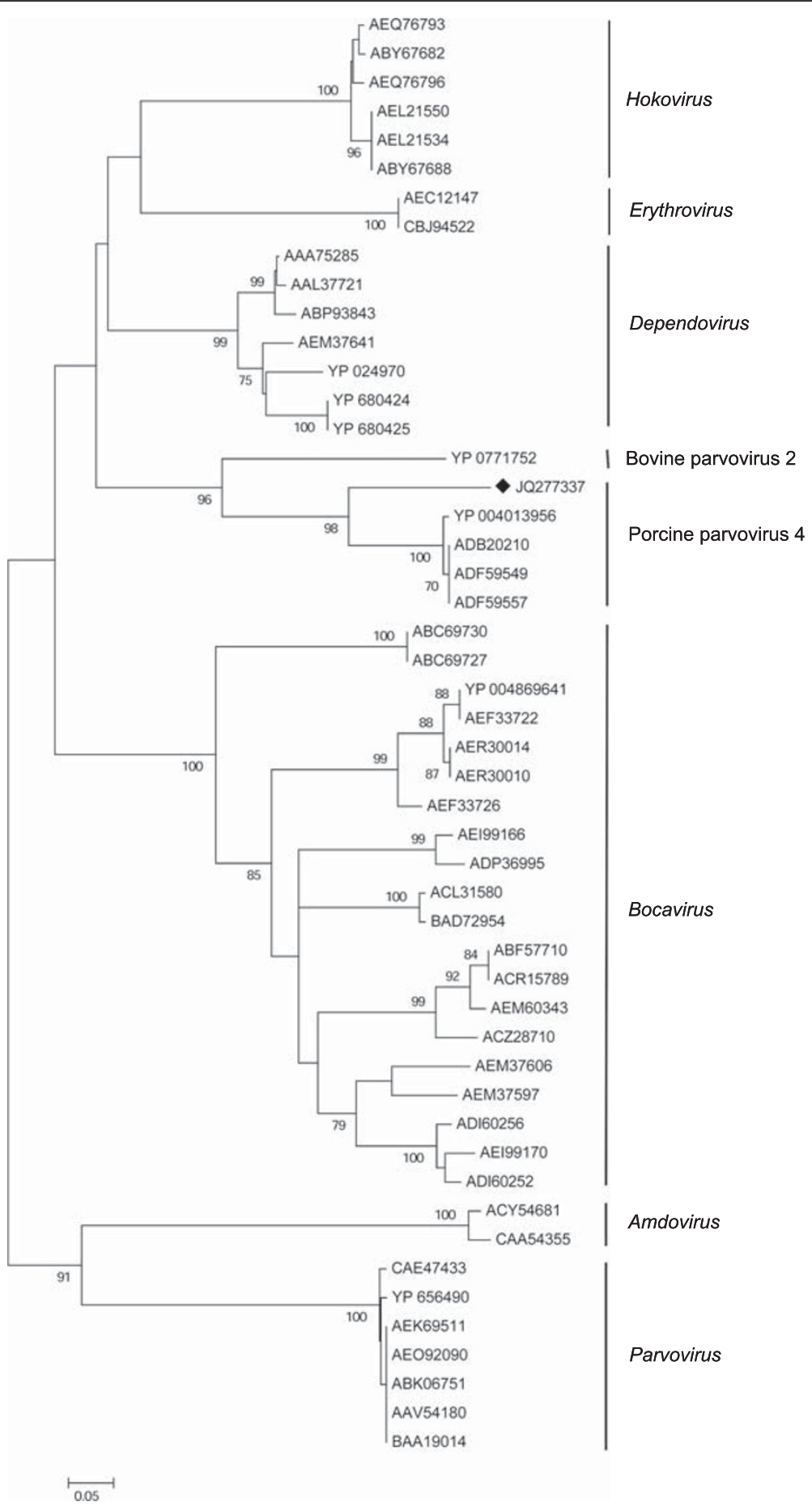

Figure 1 Neighbour-joining phylogenetic tree of Parvovirus. The Neighbour-joining tree shows the phylogenetic relationship between the bushpig PPV4 sequence (84 amino acid long) and 49 sequences available from GenBank. The bushpig PPV4 is indicated with 


\section{Torque teno sus virus}

Torque teno virus was discovered 1997 in a serum sample from a patient with posttransfusion hepatitis of unknown etiology using representational difference analysis [14]. Since then the virus has been detected and characterised in a number of species such as primates, cats, dogs and pigs [15], but the role of these viruses in disease development is still controversial. These viruses have small (approximately $2.8 \mathrm{~kb}$ ) circular DNA genomes. Torque teno virus in pigs is divided into two different species, Torque teno sus virus 1 and 2, and prevalence studies have shown that TTSuV is widely spread in pig populations across the world [16,17]. In a previous study [18], we have found that $51.6 \%$ of a sample population of domestic pigs in Uganda were carrying one or both these TTSuV variants. Although, most studies have targeted domestic pigs, TTSuV have also been found in wild boar in Europe [19].

As shown in Table 1, our data indicated the presence of both TTSuV-1 and 2 in the investigated serum samples. Both the TTSuV-1 and 2 sequence reads were located in the major open reading frame (ORF1) and all reads showed significant similarity to the respective virus in both blastn and blastx analyses.

Two of the TTSuV-1 sequence reads partially overlapped and the sequence analysis indicated a significant variation between the two and therefore two different TTSuV-1 PCR assays were designed. The results from the specific PCR assays showed that one of the TTSuV-1 variants (here named TTSuV-1a) could be found in two of the three bushpig sera while the other one (here named TTSuV-1b) was found in all three. The sequence analysis of the PCR amplified TTSuV-1 products (GenBank accession number JQ277338 - 42) showed a sequence similarity between $\mathrm{TTSuV}-1 \mathrm{a}$ and $\mathrm{b}$ on protein level at $53-54.5 \%$ in the analysed 66 amino acid region. Compared to sequences from other studies, TTSuV-1a showed a $60.6-84.8 \%$ protein sequence similarity while TTSuV-1b was more divergent (50-56\% similarity). These protein sequence identity values were similar to those seen when comparing the sequences retrieved from the GenBank with each other (59-100\% similarity). The phylogenetic tree (Figure 2) also indicated that TTSuV-1b was more divergent than the other sequences. Sequences from different parts of the world such as China, Germany, Spain, US etc. was used in the phylogenetic study however no clear geographical clustering was seen.

TTSuV-2 was confirmed in one of the bushpig sera and the amplified product GenBank accession number JQ277343) showed a protein sequence identity of 66.6$79.4 \%$ to the other TTSuV-2 sequences used in the phylogenetic study using a 313 amino acid region. This sequence identity was in the range of the similarity seen

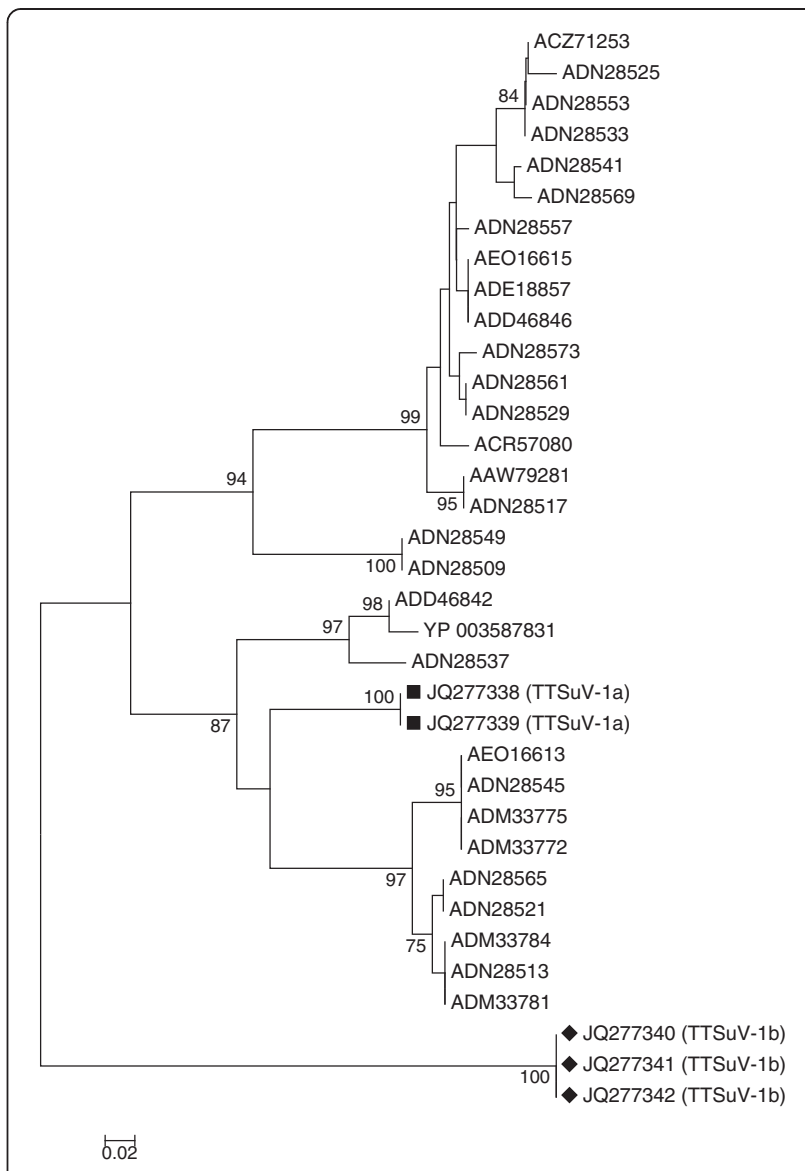

Figure 2 Neighbour-joining phylogenetic tree of TTSuV-1. The Neighbour-joining tree shows the phylogenetic relationship between the five bushpig TTSuV-1 sequences (66 amino acid long) and 30 sequences available in GenBank. The bushpig TTSuV-1a is indicated with and TTSUV-1b with

between the different TTSuV-2 sequences from other studies used for comparison (64.2-100\%). In the phylogenetic study (Figure 3) the sequenced TTSuV-2 grouped with the other TTSuVs but in its own clade.

TTSuV-1 and 2 have previously, as mentioned, been detected both in domestic pigs across the world [16-18] and wild suidae in Europe [19] and now for the first time in bushpigs on the African continent. Studies on the genetic variability of TTSuV-1 and 2 have shown a higher genetic diversity in the coding regions compared to the untranslated region [20]. The sequence analysis of both the bushpig-derived TTSuV and those from GenBank shows a high genetic variability among the different TTSuV-1 and TTSuV-2 and also shows the co-infection of two different TTSuV-1 variants and one TTSuV-2.

\section{Retrovirus}

Endogenous retroviruses are integrated in the host genome and all vertebrates investigated have been shown to carry retroviral sequences. It is estimated that up to $10 \%$ 


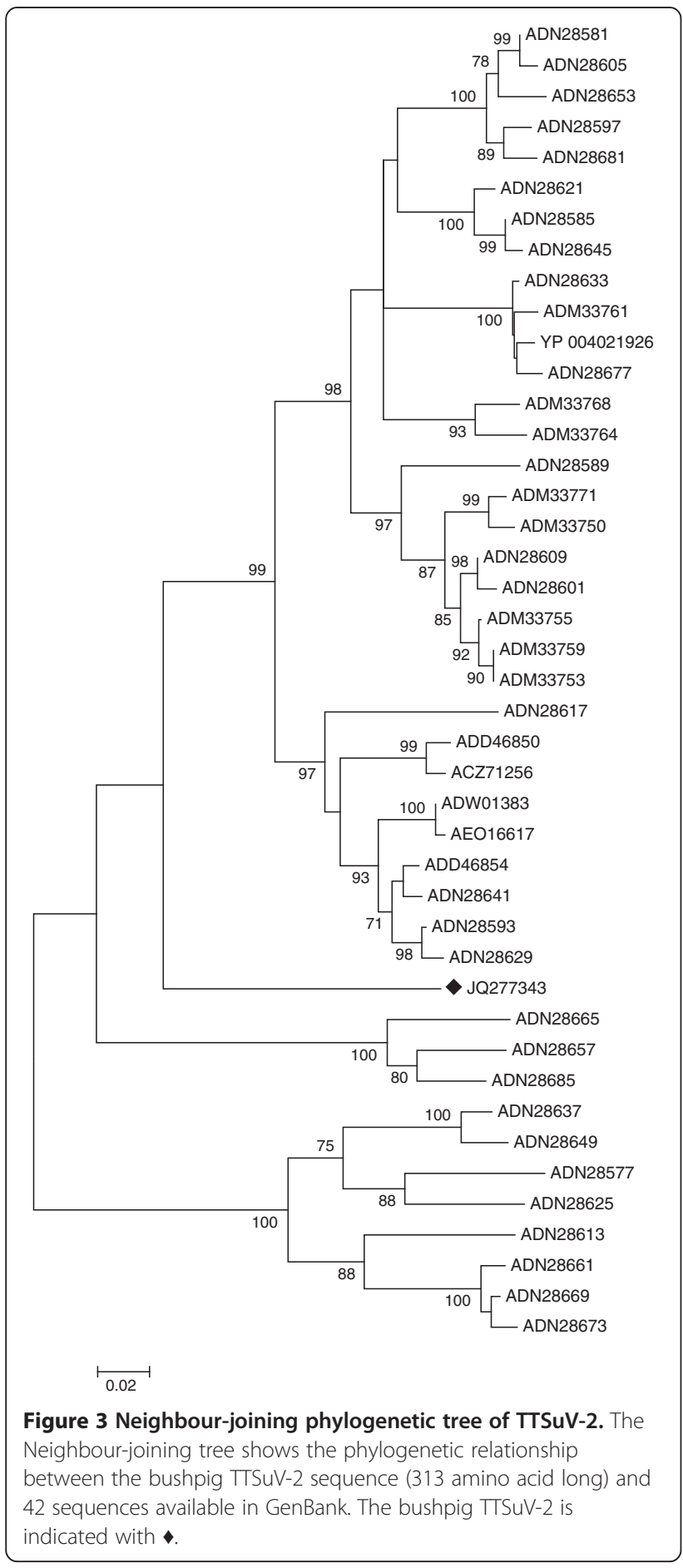

of animal genomes are retroviral elements [21]. Also the bushpig genome has been investigated and confirmed to contain PERV [22-24].

By running the specific PERV PCR on both DNA and on DNase treated RNA we could as expected see that all the bushpigs had both integrated proviral DNA and expressed PERV RNA, indicating active viral transcription and replication. The sequenced PERV products
(GenBank accession number JX566717-719) showed a high similarity (85 - 89\%) to those available in GenBank.

\section{Conclusions}

Through investigating sera collected from bushpigs in Uganda by viral metagenomics, we have for the first time showed the presence of PPV4 in a wild Suid on the African continent. The region of PPV4 investigated indicates a sequence divergence relative to previously described PPV4. In addition, novel TTSuV-1 and 2 variants were found. Further sequence analysis and prevalence studies can be used to define the genetic relationships of these viruses and their distribution in both domestic pigs and in wildlife.

\section{Methods}

\section{Samples}

The sera from three bushpigs collected from Lake Mburo National Park, Uganda in March 2010, as part of a research project on African swine fever epidemiology were used in this study. The animals were captured using game capture nets $(50 \times 3 \mathrm{~m}, 150 \mathrm{~mm}$ square mesh, $3.5 \mathrm{~mm}$ nylon braid khaki, ALNET Ltd, South Africa) with assistance from Uganda Wildlife Authority (UWA) staff, and sedated with zolazepam and tiletamine (Zoletil forte vet $50 \mathrm{mg} / \mathrm{ml}+50 \mathrm{mg} / \mathrm{ml}$, Virbac Laboratories, France) before blood sampling from the saphenous vein. The Ministry of Agriculture Animal Industry and Fisheries and Uganda Wildlife Authority, together with Makerere University are mandated to carry out animal disease investigations in livestock and wildlife in the country. This is done by veterinarians who handle the animals under internationally recognized guidelines.

\section{Sample preparation, nucleic acid extraction and random PCR}

Fifty microliters of serum was aliquoted for the RNA and DNA extraction respectively. One hundred and fifty microliter of 1x DNase buffer (Roche, Mannheim, Germany) was added to each aliquot of serum after which the sample was treated with nucleases - $100 \mathrm{U}$ DNase (Roche, Mannheim, Germany) and $2 \mu \mathrm{g}$ RNase (Invitrogen, Carlsbad, CA, USA) for two hours at $37^{\circ} \mathrm{C}$ in order to degrade the host nucleic acid. Trizol was added to one of the two aliquots and RNA was extracted using a combination of Trizol and Qiagen RNAeasy kit. DNA was extracted using the Qiagen DNAeasy mini extraction kit according to the manufacturer's instructions and eluted in $50 \mu$ l elution buffer (EB). The DNA and RNA were amplified by random PCR as described earlier [25]. Before sequencing, the primers were cleaved using EcoRV (NEB, Ipswich, MA, USA) and the cleaved product was purified using the Qiagen PCR purification kit (Qiagen, Hilden, Germany) and eluted in $30 \mu \mathrm{EB}$. 


\section{High-throughput sequencing and data analysis}

The purified product was sequenced on $1 / 8^{\text {th }}$ of a pico titre plate using the 454 technology by Roche at Inqaba Biotech (South Africa). The sequences were analysed through quality check and removal of very short sequences before being assembled using CLC genomic workbench v4.6 (http://www.clcbio.com/index.php). Blastn and blastx searches were performed through the Camera 2.0 portal $[26,27]$ and searches through NCBI (http://www.ncbi.nlm.nih.gov/blast/Blast.cgi). The viral blast hits with an e-value of $10^{-4}$ or lower were further analysed.

\section{Confirmation PCRs, sequencing and phylogenetic studies}

PCR primers were designed based on the reads from the 454-sequencing run (Table 2) and PCR assays were set up with the aim to look for each individual virus in each bushpig sera. For the RNA viruses cDNA synthesis was performed prior to PCR using Superscript III (Invitrogen, Carlsbad, CA, USA) and random primers according to the manufacturer's instructions. The PERV RNA was treated with DNase prior to the cDNA synthesis and both a "+" and a "-" RT cDNA synthesis reaction was performed. The PCR using each specific primer pair (Table 1) was performed according to the following procedure: $1 \mathrm{x}$ PCR buffer, $2.5 \mathrm{mM} \mathrm{MgCl}_{2}, 1.0 \mathrm{mM}$ dNTP, $0.4 \mu \mathrm{M}$ forward primer and reverse primer each, and 1.25 U AmpliTaq Gold DNA polymerase (Applied Biosystems, Foster City, CA, USA). For each reaction, two $\mu \mathrm{l}$ DNA or cDNA from each respective bushpig was used. The amplification was performed with the following reaction conditions: a 12 minute enzyme activation step at $95^{\circ} \mathrm{C}$ followed by 39 cycles of $95^{\circ} \mathrm{C}$ for 30 seconds, $58^{\circ} \mathrm{C}$ for 30 seconds and $72^{\circ} \mathrm{C}$ for 90 seconds, finishing with

\section{Table 2 Primers for verification}

\begin{tabular}{ll}
\hline Primer & Sequence 5'- 3' \\
\hline TTSuV-1a_F & TCC CAG CAG AAG ATG TAG TC \\
TTSuV-1a_R & GGA TGG TGG CCT CTA CTA C \\
TTSuV-1b_F & GCA GCA TAA CGC TAG GCT G \\
TTSuV-1b_R & AGA GGA AAT GGG CTA CCT G \\
PPV4_F & CTC TGA TAA TGT ATT ACT GGT C \\
PPV4_R & AAG AAA GAT CCT TCT GTT ACA \\
GB Hepatitis C virus_F & CTG CCT CAA CGT TGA GGC AG \\
GB Hepatitis C virus_R & ACG ACG TAG CAG TGG TAG AT \\
Sclerotinia hypovirulence & CGC ATC ACG GTC AAG TTT GA \\
associated virus_F & \\
Sclerotinia hypovirulence & TTA CAT TGC TTC GTC GAC TTC \\
associated virus_R & \\
PERV_F & ATG GGA GCT GGG TCC AAT C \\
PERV_R & CCT TAC GTT TGA CTC TCG AC \\
\hline
\end{tabular}

Primers used for the detection and sequencing of the found viruses. one cycle for 10 minutes at $72^{\circ} \mathrm{C}$. The PCR products were visualized on a $1.5 \%$ agarose gel. The PCR-positive products were purified using the QIAquick PCR purification kit (Qiagen, Hilden, Germany) according to the manufacturer's instructions and eluted in $25 \mu \mathrm{EB}$. The purified products were sequenced with standard Sanger sequencing using Big Dye Termination kit (Applied Biosystems, Foster City, CA, USA) according to the manufacturer's instructions. The obtained chromatograms were edited using SeqMan (Lasergene 9, DNASTAR Inc., Madison, USA). Sequence identity plots were performed using the Bioedit software [28]. ClustalW as well as the phylogenetic analyses were carried out using Mega 5 [29]. The phylogenetic trees were constructed using the Neighbour-joining algorithm with p-distances and with a bootstrap value of 1000 .

\section{Competing interests}

The authors declare that they have no competing interests.

\section{Authors' contributions}

ALB has performed the laboratory experiments, contributed to the study design, data analysis, manuscript draft and final manuscript preparation. KS and CM coordinated the field work and contributed to study design, data analysis and final manuscript preparation. EO and PA coordinated the bushpig capture and contributed to the final manuscript preparation. $A R O$, $\mathrm{SK}, \mathrm{RB}$ and SB contributed to the final manuscript preparation. MB contributed to study design, data analysis and final manuscript preparation. All authors have read and approved the final manuscript.

\section{Acknowledgements}

We would like to thank our colleagues Denis Muhangi and Susan Ndyanabo for technical assistance in the laboratory and Uganda Wildlife Authority staff for assistance in the field. Financial support for this study was provided by the Swedish International Development Cooperation Agency (Sida; SWE2009-081), the Swedish research Council Formas (221-2009-1984), the Swedish Ministry of Foreign Affairs as part of its special allocation on global food security (through the Swedish University of Agricultural Sciences, SLU) and by the Award of Excellence awarded to SB by SLU.

\section{Author details}

'Department of Biomedical Sciences and Veterinary Public Health, Section of Virology, Swedish University of Agricultural Sciences, Uppsala, Sweden. ${ }^{2}$ Department of Virology, Immunobiology and Parasitology (VIP), National Veterinary Institute (SVA), Uppsala, Sweden. ${ }^{3}$ Department of Biology, Makerere University, College of Natural Sciences. School of Biological Sciences, Box 7026, Kampala, Uganda. ${ }^{4}$ International Livestock Research Institute (ILRI), Nairobi, Kenya. ${ }^{5}$ National Animal Disease Diagnostics and Epidemiology Centre (NADDEC), Ministry of Agriculture Animal Industry and Fisheries, Entebbe, Uganda. ${ }^{6}$ Uganda Wildlife Authority, Kampala, Uganda.

Received: 19 March 2012 Accepted: 5 September 2012

Published: 11 September 2012

\section{References}

1. Perry BD, Grace D, Sones K: Livestock and Global Change Special Feature: Current drivers and future directions of global livestock disease dynamics. Proc Natl Acad Sci USA 2011.

2. Daszak P, Cunningham AA, Hyatt AD: Emerging infectious diseases of wildlife-threats to biodiversity and human health. Science 2000, 287:443-449.

3. Siembieda JL, Kock RA, McCracken TA, Newman SH: The role of wildlife in transboundary animal diseases. Animal health research reviews / Conference of Research Workers in Animal Diseases 2011, 12:95-111.

4. Blomström A-L: Viral metagenomics as an emerging and powerful tool in veterinary medicine. Vet Q 2011, 31:107-114. 
5. Tang P, Chiu C: Metagenomics for the discovery of novel human viruses. Future Microbiol 2010, 5:177-189.

6. Delwart EL: Viral metagenomics. Rev Med Virol 2007, 17:115-131.

7. Jori F, Bastos AD: Role of wild suids in the epidemiology of African swine fever. EcoHealth 2009, 6:296-310.

8. Hueffer K, Parrish CR: Parvovirus host range, cell tropism and evolution. Curr Opin Microbiol 2003, 6:392-398.

9. Mengeling WL, Lager KM, Vorwald AC: The effect of porcine parvovirus and porcine reproductive and respiratory syndrome virus on porcine reproductive performance. Anim Reprod Sci 2000, 60-61:199-210.

10. Lau SK, Woo PC, Tse H, Fu CT, Au WK, Chen XC, Tsoi HW, Tsang TH, Chan JS, Tsang DN, et al: Identification of novel porcine and bovine parvoviruses closely related to human parvovirus 4. J Gen Virol 2008, 89:1840-1848.

11. Blomström AL, Belak S, Fossum C, McKillen J, Allan G, Wallgren P, Berg M: Detection of a novel porcine boca-like virus in the background of porcine circovirus type 2 induced postweaning multisystemic wasting syndrome. Virus Res 2009, 146:125-129.

12. Cheung AK, Wu G, Wang D, Bayles DO, Lager KM, Vincent AL: Identification and molecular cloning of a novel porcine parvovirus. Arch Virol 2010, 155:801-806.

13. Huang L, Zhai SL, Cheung AK, Zhang HB, Long JX, Yuan SS: Detection of a novel porcine parvovirus, PPV4, in Chinese swine herds. Virol J 2010, 7:333.

14. Nishizawa T, Okamoto H, Konishi K, Yoshizawa H, Miyakawa Y, Mayumi M: A novel DNA virus (TTV) associated with elevated transaminase levels in posttransfusion hepatitis of unknown etiology. Biochem Biophys Res Commun 1997, 241:92-97.

15. Okamoto H: $\Pi$ T viruses in animals. Curr Top Microbiol Immunol 2009, 331:35-52.

16. Blomström AL, Belak S, Fossum C, Fuxler L, Wallgren P, Berg M: Studies of porcine circovirus type 2 , porcine boca-like virus and torque teno virus indicate the presence of multiple viral infections in postweaning multisystemic wasting syndrome pigs. Virus Res 2010, 152:59-64.

17. Segales J, Martinez-Guino L, Cortey M, Navarro N, Huerta E, Sibila M, Pujols J, Kekarainen T: Retrospective study on swine Torque teno virus genogroups 1 and 2 infection from 1985 to 2005 in Spain. Vet Microbiol 2009, 134:199-207.

18. Brink M, Stahl K, Masembe C, Okurut AR, Berg M, Blomstrom AL: First time molecular detection and phylogenetic relationships of torque teno sus virus 1 and 2 in domestic pigs in Uganda: further evidence for a global distribution. Virol J 2012, 9:39.

19. Martinez L, Kekarainen T, Sibila M, Ruiz-Fons F, Vidal D, Gortazar C, Segales J: Torque teno virus (TTV) is highly prevalent in the European wild boar (Sus scrofa). Vet Microbiol 2006, 118:223-229.

20. Cortey M, Macera L, Segales J, Kekarainen T: Genetic variability and phylogeny of Torque teno sus virus 1 (TTSuV1) and 2 (TTSuV2) based on complete genomes. Vet Microbiol 2011, 148:125-131.

21. MacLachlan JN, Dubovi EJ: Fenner's Veterinary Virology. Fourthth edition. London: Academic Press; 2001

22. Do Nascimento FF, Gongora J, Tristem M, Lowden S, Moran C: Distinctive differences in long terminal repeat sequences between gamma1 endogenous retroviruses of African and Eurasian suid species. Infect Genet Evol 2011, 11:686-693.

23. Do Nascimento FF, Gongora J, Charleston M, Tristem M, Lowden S, Moran C: Evolution of endogenous retroviruses in the Suidae: evidence for different viral subpopulations in African and Eurasian host species. BMC Evol Biol 2011, 11:139.

24. Patience C, Switzer WM, Takeuchi Y, Griffiths DJ, Goward ME, Heneine W, Stoye JP, Weiss RA: Multiple groups of novel retroviral genomes in pigs and related species. J Virol 2001, 75:2771-2775.

25. Blomström AL, Widen F, Hammer AS, Belak S, Berg M: Detection of a novel astrovirus in brain tissue of mink suffering from shaking mink syndrome by use of viral metagenomics. J Clin Microbiol 2010, 48:4392-4396.

26. Seshadri R, Kravitz SA, Smarr L, Gilna P, Frazier M: CAMERA: a community resource for metagenomics. PLoS Biol 2007, 5:e75.

27. Sun S, Chen J, Li W, Altintas I, Lin A, Peltier S, Stocks K, Allen EE, Ellisman M, Grethe J, Wooley J: Community cyberinfrastructure for Advanced Microbial Ecology Research and Analysis: the CAMERA resource. Nucleic Acids Res 2011, 39:D546-551.
28. Hall T: BioEdit: a user-friendly biological sequence alignment editor and analysis program for Windows 95/98/NT. Nucleic Acids Symp Ser 1999, 41:95-98.

29. Tamura K, Dudley J, Nei M, Kumar S: MEGA4: Molecular Evolutionary Genetics Analysis (MEGA) software version 4.0. Mol Biol Evol 2007, 24:1596-1599.

doi:10.1186/1743-422X-9-192

Cite this article as: Blomström et al:: Viral metagenomic analysis of bushpigs (Potamochoerus larvatus) in Uganda identifies novel variants of Porcine parvovirus 4 and Torque teno sus virus 1 and 2. Virology Journal 2012 9:192.

\section{Submit your next manuscript to BioMed Central and take full advantage of:}

- Convenient online submission

- Thorough peer review

- No space constraints or color figure charges

- Immediate publication on acceptance

- Inclusion in PubMed, CAS, Scopus and Google Scholar

- Research which is freely available for redistribution 